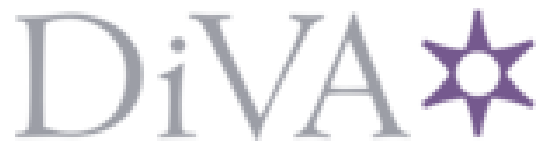

http://www.diva-portal.org

\title{
Postprint
}

This is the accepted version of a paper presented at NordiCHI 2O18, 1-3 october 2018.

Citation for the original published paper:

Helms, K., Fernaeus, Y. (2018)

Humor in Design Fiction to Suspend Disbelief and Belief

In: NordiCHI '18 Proceedings of the 1oth Nordic Conference on Human-Computer Interaction

https://doi.org/10.1145/3240167.3240271

N.B. When citing this work, cite the original published paper.

Permanent link to this version:

http://urn.kb.se/resolve?urn=urn:nbn:se:kth:diva-235951 


\section{Humor in Design Fiction to Suspend Disbelief and Belief}

Karey Helms

KTH Royal Institute of Technology

Stockholm, Sweden

karey@kth.se

YIva Fernaeus

KTH Royal Institute of Technology

Stockholm, Sweden

fernaeus@kth.se

\begin{abstract}
This paper investigates humor as a resource and strategy for design with discourse as an intended outcome. While humor can incite empathy and understanding, it can also lead to alienation and disengagement. Through the detailing of the pre-narrative and narrative processes of a design fiction, we describe why and how elements of humor, in particular puns, parody, and pastiche, were employed. Following the presentation of the fiction and its use in the design of an exhibition of diegetic prototypes, the paper presents responses from participants and audience members to reflect upon how the humor was received. Following a discussion on these reflections, as the near-future scenario was written four years prior and is now situated within the present-day, it then concludes with a post-mortem reflection on the floating nature of humor.
\end{abstract}

\section{Author Keywords}

Design fiction; future scenario; humor; satire; sustainability.

Permission to make digital or hard copies of all or part of this work for personal or classroom use is granted without fee provided that copies are not made or distributed on the first page. Copyrights for components of this work owned by others than the author(s) must be honored. Abstracting with credit is permitted. To copy otherwise, or republish, to post on servers or to redistribute to lists, requires prior specific permission and/or a fee. Request permissions from Permissions@acm.org. NordiCHI'18, September 29-October 3, 2018, Oslo, Norway

(02018 copyright is held by the owner/author(s). Publication rights licensed to ACM. ACM ISBN 978-1-4503-6437-9/18/09..\$15.00

https://doi.org/10.1145/3240167.324027

\section{ACM Classification Keywords}

H.5.m [Information interfaces and presentation (e.g., $\mathrm{HCl})$ ]

\section{Introduction}

This paper is driven by an investigation of humor as a strategy in design fiction with the intention to provoke discourse and reflection around sustainability. While humor can be 
regarded as a potential resource in understanding or emphathizing with different perspectives, it can also risk disengagement or alienation [28]. This is particularly salient in Research through Design [44]: a community drawing upon the participatory nature of design in which building empathy and trust are essential, and in which academic results should be rigorously communicated without further need of interpretation. Explicit or implicit use of humor in this context might contribute to a latent fear of being misunderstood, which is already prevalent in a research discipline drawing upon the imaginative and tacit qualities of design. However, making something funny or silly need not imply that it shouldn't be taken seriously [5]. Recent research around societal and political communication even suggests the opposite, whereby the topics we take seriously might most warrant or illicit a humorous overlay [38]. In $\mathrm{HCl}$, this perspective can be seen in the engagement of taboo topics in which humor is a strategy for approachability and dialogue, such as women's health $[1,41]$.

Yet while a framework for the design of humorous products has been proposed [43], it is still under investigated how $\mathrm{HCl}$ design researchers, especially those engaging in future scenarios and design fictions, might draw upon humor as both a narrative resource and intended outcome, attending to its structure and flow, with additional consideration to the floating nature by which culture, context, and time can quickly shift those laughing to those being laughed at. Although unintentional and intentional ridicule can be mutually harmful for both an audience and design researchers, it can also serve as a polemical resource through satire and irony by way of juxtaposition $[11,26]$. While this paper engages with both satire and irony, it is particularly interested in comedic humor, an element not required in either, which is considered to involve laughter or amusement and might also contribute to discourse.
To explore this topic, we will present a design fiction created four years ago for this purpose, and reflect back on what we now see as the main insights of this process from a designer's perspective. Situated within the domestic context of sustainable $\mathrm{HCl}$, the intended outcomes of The Family Circuit: A New Narrative of American Domesticity were to provoke individuals to reflect upon their current habits of energy consumption, consider the future implications of these actions, and question a willingness to make sacrifices for a cleaner environment.

The design fiction was grounded upon the provocation "What if you were required to produce all the energy you desire to consume?" and is set within the near-future fictional American town of Newtown. However, crafted in the spring of 2014 and with the described events taking place in June of 2018, the "near-future" is now present-day at the time of writing this paper, which contributes to a postmortem reflection on potential new meanings within the narrative relative to contemporary political events, highlighting challenges in how academic design fictions can be revisited and interpreted of over time.

Subsequent to a background that motivates the use of humor in the context of a design fiction, the paper details the pre-narrative process, emphasizing a framing of the problem space, development of design guidelines, and origins of concepts integrated into the resulting scenario and use of the scenario. The paper next describes the process of writing the fiction, drawing upon puns, parody, and pastiche as narrative resources. It then presents the resulting scenario and its use for the design of an exhibition featuring an ecosystem of diegetic prototypes. Following responses from participants involved in the production and spectators from exhibitions, the paper concludes with lessons learned and a post-mortem reflection. 


\section{Background}

Design is widely regarded as a future-oriented practice in which designers aim to transform the existing into the preferred [37]. Whether to solve problems for better futures or generate opportunities for novel experiences, this inherent focus on futures is evident within the manifestation of design exemplars and technological envisionings [42] and the many methods whereby designers and design researchers reflectively engage with materials to synthesize findings, prototype alternatives, and materialize potentials. Common examples in an $\mathrm{HCl}$ design process that employ elements of fiction to engage with futures include personas, user stories, and scenarios: methods that are taught at universities, deployed in industry, and widely researched in $\mathrm{HCl}$ [7]. However, though grounded in real user data, these methods have also been critiqued for lacking dimensionalities reflective of users and the world beyond shallow stereotypes and utilitarian goals [29]. Challenging this perceived lack of rigor and a cohesive agreement regarding the desired form and fidelity of fiction in $\mathrm{HCl}$, a growing interest in the Research through Design community has emerged, drawing upon an array of disciplines [35], literary techniques [4, 27], and theoretical frameworks [25], contributing to a body of work often classified as design fiction.

Design fiction, as proposed by Julian Bleecker, is a futureoriented design and research method that opens opportunities to consider not only what could be, but also what should be, through "material objects that help tell stories about the future"[3]. Embedded within this speculative tone is a reciprocal informing of the real and the imagined, or the present and the future, in which by designing for a world that does not yet exist, values of the current world are called into question [12]. This implied critique can be seen to position design fiction towards Critical or Speculative Design practices such as those defined by Dunne and
Raby, which invite reflection and discourse by calling into question the status quo through satire [14]. While satire as ridicule for social criticism through humor or wit might be evident in many design research practices [26], overt irony might distance design work from the every day as it instead becomes shocking or extreme [23]. Similar to speculative practices, design fiction shares this alliance with the every day as a resource of familiarity and normality from which fictional design artifacts can orient critique, exploration, or solutions.

Design fiction artifacts are referred to as diegetic prototypes, or seemingly everyday objects that only exist within a fictional world [21]. By making use of a narrative to contextualize them, diegetic prototypes in turn can also function as plot devices that reveal tension, motivate drama, and ignite new peculiar behaviors while suggesting broader implications of technology in everyday practices [3]. As described by Bruce Sterling, design fiction is ultimately "the deliberate use of diegetic prototypes to suspend disbelief about change" [40], foregrounding plausibility as a significant element of this method to employ a fictive future reflective of contemporary values.

This quest for plausibility is not without concern in legitimizing design fiction as a research method. In particular, Coulton et al. underline design fiction as inherently deceptive and thus challenging research ethics [8]. This concern is similarly echoed in what Holmquist refers to as cargo cult design, in which artifacts of the design process are mistaken for real representations of a future state if appropriate consideration is not given to transparently initiate an audience into the intent of the artifact [20]. Film and television has long recognized the societal influence and potential implications of presenting false or misleading science on screen, contributing to an influx of scientists into produc- 
tion rooms [22]. Blythe et al. propose eliminating plausibility altogether by employing absurdity through silliness as one possible path to mitigate deception while still opening conversations about alternative futures [5]. This embracement of ridiculousness without ridicule rejects irony for a suspension of belief.

Exactly how humor might take form in academic design fictions that aim for solutions or critique is still an open question to explore. While engaging with potentially humorous elements of technology and interaction appears valuable to capture interest and give meaning while unequivocally conveying it as fiction, it poses challenges worthy of further investigation. Thus, rather than aiming exclusively for plausibility, this paper investigates the possibility of both a suspension of disbelief and belief by not rejecting irony and satire, but in addition to them, drawing upon comedic humor as a resource to evoke laughter and amusement.

\section{Pre-Narrative Process}

Prior to the writing of the design fiction, three pre-narrative activities were conducted. As the project is situated within the domestic context of sustainable $\mathrm{HCl}$, the first activity was a framing of the problem space to ground a counterfactual what-if-question [14]. The second activity included fieldwork for a humoristic framing of design guidelines. The third activity comprised ideations to generate absurd yet everyday conceptual directions and details.

Although the design fiction is situated in the United States, the described process took place in Sweden. Overall, seventeen participants in the United States remotely participated in fieldwork, sixteen interaction and industrial design students from a Swedish design school were involved in ideation and production, and three participants from the United States participated in the production.

\section{Problem Space}

In addition to the prevalence of the domestic context in sustainable $\mathrm{HCl}[18,33,34]$, this domain was chosen due to the complex relationship between electrical energy practices and notions of consumption and conservation that began with electricity's integration into households in the late 19th century. Following technical and cultural challenges for industry, such as uneven daily distribution of electricity and superstitious preconceptions, end consumption was more a display of wealth than domestic utility [30]. The subsequent development of new electrical appliances, such as the toaster, were often invented to fill electricity gaps during non-peak hours, while marketing campaigns propagated the myth of the mechanical servant to preserve gendered domestic labor [16]. Contemporary trends have since seen a shift from conspicuous consumption to conspicuous conservation, in which people engage with environmentally friendly technologies to signal high social status [36]. How this evolving yet inherent friction between consumption and conservation as manifested in domestic product innovation and social norms might be applied to a domestic production of electrical energy opened a design space.

Formulated as a what-if-question to extend from a presentreality to a near-future for constructive social criticism, the design space intended to question values through surfacing desires by asking "What if you were required to produce all the energy you desire to consume?" Drawing upon previous work that engages with energy as a design material, notions of direct experience [32], consequentiality [2], and ownership and scarcity [31] were extracted as positions from which to provoke discourse. Intended outcomes included challenging individuals to reflect upon their relationship with electrical energy usage, consider broader implications of this usage over time and beyond individual consumption, and elicit a willingness to make sacrifices for 


\section{Design Guidelines}

1. Physically explicit options and operations over implicit and automated interactions with electrical energy to counter the common misconception of electricity as an abstract and disembodied phenomenon.

\section{Conflict between conve-} nience and control in which efficiency and seamlessness are superseded by ownership and a fear of scarcity to create dilemma for both characters and audiences to experience.

3. Facilitation of chain reactions that emphasize actual or potential interdependent technologies, actions, and desires to reflect on the complexities of real-use contexts instead of single-appliance usage.

4. Overt status symbols that give both social and technological feedback for individuals and communities to emphasize conspicuous consumption and conservation.

\section{Creation of a closed circuit} in which energy production and consumption is a self-contained system that leads to a lack of conflict resolution. sustainable alternatives. While similar motivations have been taken on by design fiction SFUture [19] and value fiction Is This Your Future? [13], this work differs from the former by not suggesting a solution through an explicit future that advocates for aspirational values embedded within the scenario; and it differs from the latter through its social emphasis while drawing upon emotional appeals other than fear as might be associated with dystopian visions.

\section{Fieldwork}

Fieldwork first investigated everyday experiences with electrical energy consumption. Borrowing from cultural probes [17] and auto-ethnography [9], fourteen participants located in the United States were recruited through socia media to document interactions with electrical energy over the course of three twenty-four-hour time intervals. Drawing upon a theoretical investigation of direct experiences with electrical energy as a framework for documentation and analysis [32], participants were asked to photograph the interaction, context, and furthest trace of the electrical power source. After each time period, the resulting images were printed for card sorting, resulting in three interactional themes. The first theme was an emphasis on background or implicit interactions with electricity, in particular automatic lights and centralized systems. A contrast in perceived multiplicities of interaction between distributed and centralized systems surfaced a second theme of convenience. The third theme was interdependent and networked interactions, such as ecosystems of appliances for singular experiences and a tethering of devices to enhance functionality.

Fieldwork next investigated everyday experiences with electrical energy production. Members of off-grid communities were interviewed to investigate self-sufficient lifestyles as non-normative practices. In the context of this project, living off-grid was defined as not being connected to the national electrical grid and often included living without other public utilities. Due to obvious connectivity implications of such a lifestyle, interviews were restricted to those who maintained an internet presence such as a personal blog and thus could be contacted online. Interviews were conducted through email and focused on motivations and challenges, raising three additional themes. The first theme was an increased control over home infrastructures and the resulting knowledge that enabled notions of empowerment and selfgovernance. The second theme was a continued motivation for a self-sufficient lifestyle by perceived envy and awe expressed by those with similar values. While this suggestion of conspicuous conservation might be biased relative to the active maintenance of an online presence, it was also reflectively recognized that such patterns were being looked for and hence focused on particular ways in which it was enacted. The third theme was an expressed potential for resolution of past unsustainable behaviors through suffering and sacrifice due to a disconnection with utilities.

\section{Design Guidelines}

The resulting themes from fieldwork were used to formulate five design guidelines for the design fiction. The guidelines had both ideological and narrative purposes: to motivate discussions of the experiential and social qualities that may affect and transform relationships, while also configuring a paradox between what these qualities are and an opposing condition. Steering design decisions towards tension, or incongruous and unexpected situations, would serve as a resource for humor to arise [28].

\section{Ideation}

Ideation generated conceptual directions and details for the narrative. Activities were situated within the domestic environment to narrow the design space and draw upon the historical complexity of electricity in the home. By returning 


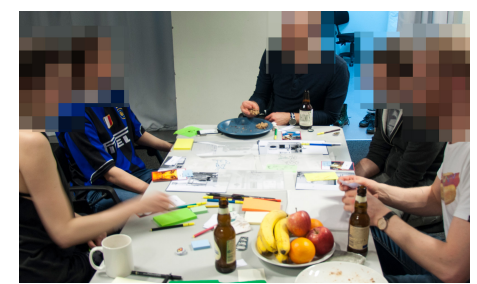

Figure 1: Workshop on energy production. The workshop was video recorded and later reviewed for additional design material. (c) Karey Helms.

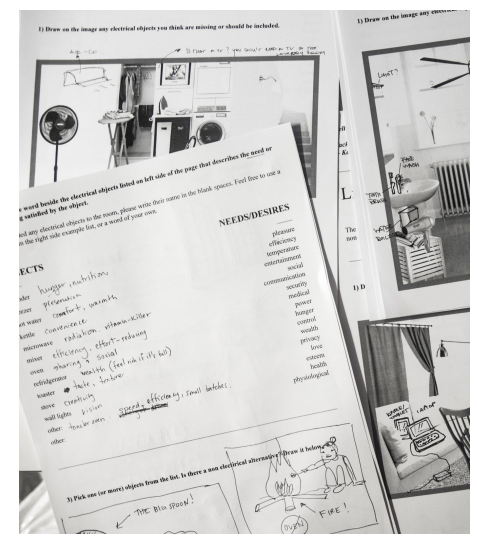

Figure 2: Worksheets on energy consumption. (C) Karey Helms. to the core provocation "What if you were required to produce all the energy you desire to consume?", two activities were formulated: a workshop on production and worksheets on consumption. As the intention was to provoke reflection, the workshop was structured to extrapolate speculative moments of domestic tension that, though possibly absurd, might lead to energy production; whereas the worksheets were designed to uncover personal needs and desires that might be fulfilled by domestic objects that consume energy.

The workshop on energy production was a four-hour evening activity in which five industrial and interaction design students were invited to role play a family (Figure 1). At the beginning of the event, each participant was given a role card and an opportunity to describe their character, detailing aspirations and anxieties. Next, parental figures were asked to distribute snacks and refreshments relative to their parental values and children's prior behavior. Following this deliberate instigation of a power imbalance to foster friction, participants brainstormed and role played additional scenarios aided by emotional prompt cards and plotted incidents on a fictive home. Speculative tensions that emerged included taboo themes of adolescent masturbation, marital sexuality, weight management, sibling rivalry, parental manipulation, neighborhood social status, and targeted advertisements with associated privacy concerns. This workshop generated quirky characteristics, interactions between personas, and energy harvesting concepts, which would later be brought directly into the scenario.

The worksheets on energy consumption were distributed through social media and included four activities (Figure 2). The first featured a domestic space from the fictive home used in the workshop, on which participants were asked to draw relevant electrical objects. The second listed a column of needs or desires and a column of electrical objects derived from field studies and background literature, and asked participants to associate items from the two columns as well as supplement either list. The third activity asked participants to pick one or more electrical objects from the previous list and draw a non-electrical alternative to surface potentially inconvenient or inefficient possibilities. The final activity asked participants to draw how they might harvest energy from their body by employing mechanical interventions to power devices from the previous activities, thereby connecting consumption with production. The worksheets surfaced objects and desires used in the scenario.

\section{Narrative Process}

The narrative was written by the first author over six weeks during which content creation frequently transitioned between story-world-building, character development, and diegetic prototype design. It took the form of a twentyminute radio show that parodies the weekly one-hour public broadcast program This American Life (TAL). TAL was chosen to imitate for its journalistic non-fiction style that uses real stories of everyday people through first-person accounts, memoirs, field recordings, or essays to illuminate broader societal themes. As "an entertaining kind of journalism that's built around plot" [24], its empathetic tone about mundane events affords plausibility with a "usercentered" feel while allowing for eccentric or absurd details that can be humorous and provoking. Also, TAL's multi-act structure enabled a prologue and three acts, each serving a different purpose, and a non-linear process by which the story-world was simultaneously built top-down to describe the political setting in Act 1 and bottom-up to describe the characters that inhabit the setting in Act 2. Artifacts were concurrently designed as diegetic prototypes to hint at broader sociopolitical implications as in the Prologue, and function as contextualized plot devices in Act 3 . The following expands upon how humor was engaged with in each. 


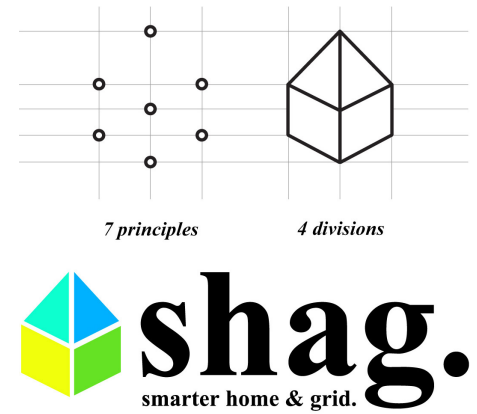

Prologue

The prologue opens with an advertisement for an energy harvesting product from ideation. By sensationalizing the everyday frustration of cleaning and repurposing a ubiquitous article as an innovative solution, it parodies an infomercial with factual details that might obscure an implicit point-of-view. For a suspension of belief, this point-of-view is made obvious through sexual innuendos and lewd puns to explicitly critique labor-saving messages and housewife portrayals evident in the history of advertisements for electrical appliances [28]. Beyond how this product might

\section{\$shag. \&shag.} change the experience of cleaning, the sexual subtext hints

\section{4 iT 4 shag. Act 1}

shag. 4shag.

Figure 3: The shag. logo is based on four divisions seven principles (local, participatory, sustainable, transparent, imaginative, accountable, and responsive). (c) Karey Helms.

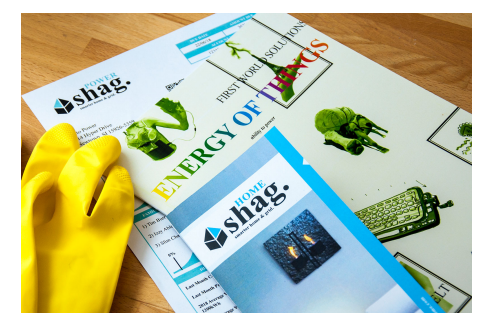

Figure 4: Mail propaganda delivered by shag. including a power bill, the Energy of Things catalog, and a home brochure. (c) Karey Helms.
While the resulting logo resembled contemporary corporate design guidelines (see Figure 3), the graphic design of mail propaganda and the infomercial differs by drawing upon older trends. This retro-looking aesthetic intends to reduce the risk of misinterpreting the materials as real, resulting in a medley of artistic imitations that parodies the counterculture ethos of Whole Earth Catalog [6] and the whimsical items of Sky Mall [39] (see Figures 4 and 5).

\section{Act 2}

The second act describes a family who are residents of the story world. Each family member's name is an obvious energy pun. In conjunction with off-kilter quotes and quirky traits, they result in literary caricatures in which exaggerated details are silly yet dark, hinting at a dystopian turn of events. Similar to personas, these details were based on real data from fieldwork and ideation, but rather than synthesizing into generalized representations of family members, peculiar idiosyncrasies remain intact and are emphasized. This excess of absurdity makes the comedic intent obvious while providing a believable stage for the particular and consequential interactions in the third act.

\section{Act 3}

The third act details a hyper-local chain of events for the family. Explicitly drawing upon the design guidelines, the scenario is prompted by an overt display of neighborhood production and consumption statistics, prompting a series of actions in which energy is physically generated and explicitly depleted. The interconnection between events is a result of scarcity and misappropriation, facilitated by character aspirations and traits, ultimately leading to a lack of conflict resolution. The implied continuation of suffering, or metaphorical closed circuit, creates a comedic opportunity to laugh at others misfortunes while provoking the audience to question how they might react in such a situation. 

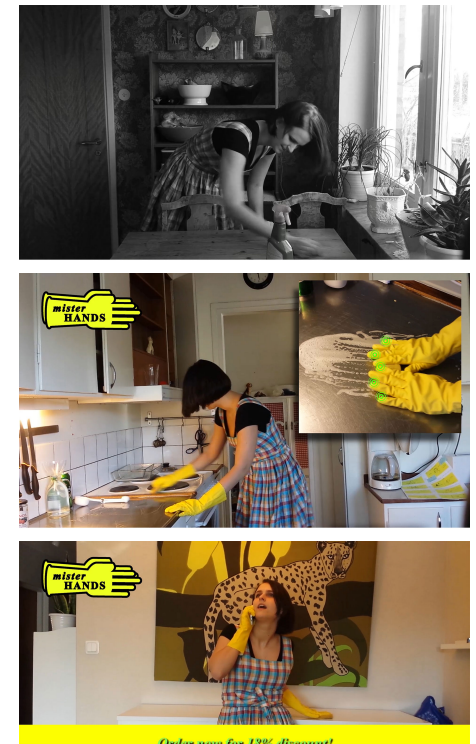

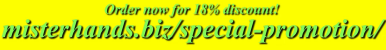
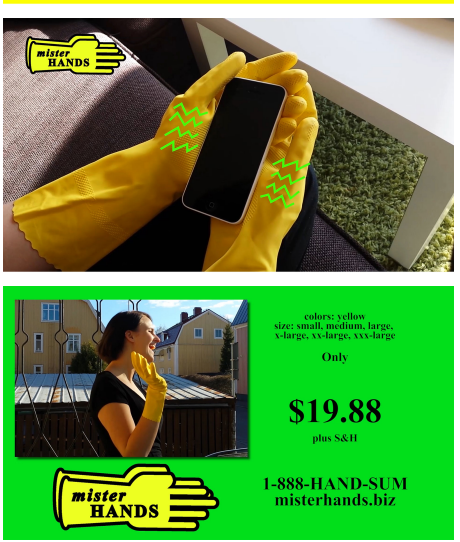

Figure 5: Infomercial screenshots for Mister Hands. (c) Karey Helms.
The Family Circuit:

\section{A New Narrative of American Domesticity}

\section{Prologue}

Advertisement: This podcast of Family Circuit: A New

Narrative of American Domesticity is supported by Mister Hands, the all-in-one housewife helper that makes it easy to wash, scrub, and polish. With cutting edge technology, durable construction, and sterilization mechanisms, you can generate electricity while cleaning in minutes. For a free trial, visit misterhands.biz/familycircuit.

Millions of women like yourself suffer from repetitive hand jobs, that leave you exhausted and without power. Cleaning a dirty home is a major culprit, stripping you of personal time and valuable energy.

\section{"When do I have time to generate electricity?"}

Introducing, Mister Hands, the comfortable daytime companions that takes full advantage of your every move and position. Ergonomically designed and fit to efficiently hug your every curve, Mister Hands features cutting edge technology, empowering you to harvest energy from surface to surface contact, vigorous friction, heavy shaking, or just holding on tight.

While most housewives run in place or put on weight to generate electricity, you're in good shape. Mister Hands makes multi-tasking easy, utilizing your everyday routines and gestures to keep your favorite devices pinging, vibrating, and providing endless entertainment.

Shop online and order Mister Hands right now!

Ivan Gass: Hey everybody. Ivan Gass here. You might have seen this on the news recently, that the Energy of Things catalog, a local, government run resource in the town of Newtown, South lota that sells and promotes personal energy harvesting tools, tips, and tricks will be transitioned into a nationally supported program in the upcoming months. Now, the catalog was originally only intended to be temporary service, just for the residents of Newtown. As l'm assuming most listeners know, and l'll dive into more details later, Newtown is a sustainable test city, where all citizens are required to produce all the energy they desire to consume. And the Energy of Things catalog contains all sorts of products, advice, resources, you name it - to help individuals generate their own electricity. Today on our program in an episode titled "You Get What You Give," we are going to uncover the political origins of the catalog, but perhaps more importantly the potential implications of this self-sufficient lifestyle.

In ACT 1, l'll give the history of Newtown. In ACT 2, I'll introduce the Power family, and in ACT 3, the Power family will invite us into a day in their lives. From WB-Clean Umeå, it's The Family Circuit, distributed by Private Recordings International. I'm Ivan Gass, stay with us.

Music: The Ballad of Speck and Pebble by Delicate Steve

Act 1: Newtown, South lota

Ivan Gass: I think we can all agree that the Clean Party's surge to power two years ago during the 2016 free electrons was the most friction the nation has experienced in decades. After the declaration of climate change as fact, which was definitely an inconvenient truth, public opinion was no doubt jolted into waves of alternating currents. This extreme polarity and variable resistance could only be bridged by the Clean Party, with their None-of-the-Above energy policy. This subtle flip switched the focus from developing every source of American-made energy on to sourcing every energy made by Americans. 


\section{Sound: Speech Recording}

President: Now, one of the biggest factors to bringing more jobs back is our commitment to energy made by Americans. The None-of-the-Above strategy is an obvious renewable energy solution that will create ampere work for citizens.

Ivan Gass: Furthermore, the Clean Party's extensive propaganda campaign was quite successful at amplifying a spike in volts, featuring slogans like:

\section{Sound: Speech Recording}

President: Fixing tomorrow today!

President: The power of YOU!

President: Why wait, mitigate!

\section{Sound: Audience Clapping}

Ivan Gass: Following the president's induction into office, he appointed former senator Dick Tator to create and develop the test city Newtown, located in South lota, to be the first fully self-sufficient master-planned community. Established under the banner of the New Suburbanism design movement and administered by the Smarter Home and Grid association, Newtown follows the guiding principles of environmentalism, smart city growth, and intelligent home automation, placing an unprecedented focus on a return to the American Dream of social mobility through hard work. Literally.

\section{Sound: Speech Recording}

President: Newtown will utilize the everyday effort of its own inhabitants as a clean, reliable, and efficient source of energy. Social mobility, or urban sprawl, will consequently be achievable for all. Moving forward, I hereby appoint former senator Dick Tator, esteemed nationally for his efficiency and capacity, to preside over the Smarter Home and Grid, or shag., association. shag. strives for Newtown to be a positive fusion of individual energy production and consumption. For I have a vision of Newtown as a powerful community, a leading example for the nation. Continuous effort is the key to unlocking this potential energy. For without energy, there is no power. To sustain that vision, we have shag., and together with your input and helping hands we can give birth to a new era.

\section{Music: America by Dusty Kid}

Ivan Gass: Sounds pretty great, right? A clean, self-sufficient, sustainable city with an abundance of work. What more could you ask for? And from here it's not hard to imagine how the Energy of Things catalog fits into the Newtown utopia. Not long after the creation of shag., their innovation and technology office launched the catalog as an allencompassing tool for the Newtown residents, to make this abundance of work easy, accessible, and even enjoyable. But how do we ever really know what a place, a service, a paradigm, is like - especially before it goes national - without stepping into shoes of those walking the walk and living the dream.

\section{Act 2: The Power Family}

Ivan Gass: When Otto and Lotta Power heard about Newtown in early 2016, they jumped on the opportunity for their family to take part in the sustainability revolution. Though, moving their two children in the heart of adolescence (Robin Power: 15 and Max Power: 10) wasn't an easy decision or transition for the family. But Otto was already well acquainted with the trials and tribulations of moving. Born in 1975 in a small coastal city to a military family of eight, Otto's childhood was nothing short of interesting. 


\section{Sound: Home Clatter}

Otto Power: Well, my father often said things like "all you need is less," or "familiarity breeds contempt," and I'm not convinced I even now know what he was talking about, but it definitely impacted my childhood.

Ivan Gass: And by impacting his childhood, he probably actually means instilling a creeping sense of personal failure. Otto often felt lost and out of place as his family frequently relocated from country to country due to his father's career. His own sensitivity to not fitting in eventually translated into placing extreme value in imperfections and defects, since well, that's how he viewed himself.

Otto Power: I guess you could call it a form of self-therapy, a way to distract myself. I spent a significant portion of middle school meticulously mending well-worn clothing from mismatched fabrics. It wasn't long before I earned myself some nicknames at school like "Patch" and "Polka."

Ivan Gass: Despite some childhood setbacks, he eventually received a B.S. in Imaginative Engineering before landing a highly coveted job in Silicon Valley as a Creative Technologist for a startup that was developing an infant gene therapy application called Parental Precision. Sponsored by toy manufacturers and pharmaceuticals, Otto's specific role in the venture was coding an algorithm for a prenatal personality generator to be used by expecting parents during their first trimester. Since this particular component of the service emphasized exactitude with the chosen genetic manipulations, Otto's spontaneous decision late one night to incorporate a random quirk generator as a hidden feature was not appreciated. Initially unnoticed for over a year, a billion-dollar class action lawsuit eventually hit the startup as the first generation of modified babies began speaking with incompatible yet distinguishable regional accents, say- ing the "Bahston mah" or the "New Yorkah ovah deh." He was immediately fired without severance pay.

Otto Power: It was pretty rough after that. I didn't know if anyone would hire me. And I thought I was just putting the creative in Creative Technologist. Luckily though, after a pretty shitty year, a former intern of my dad set me up with a job as a Senior Incident Designer at the Conduct Laboratory: a government consultancy for the Behavioral Development. Essentially, I design political scandals to generate publicity.

Ivan Gass: And it's quite perfect actually, a childhood spent searching for the positives in things different and defected, now manifested in exposing flaws and designing affairs, all for positive publicity. Because of course all publicity is good publicity.

Sound: Home Clatter and Baby Crying

Otto Power: I like to say "there are no such things as mistakes, only happy little accidents."

Ivan Gass: Which is exactly how he responded when his seventeen-year-old daughter Robin told her parents she was pregnant last year. His wife Lotta though, was less than thrilled. As a typical Millennial, Lotta Power has always been very concerned with the opinions and approval of others. A teen pregnancy in the family was not a favorable situation, but Lotta views life as a team sport, her family playing first string, and a baby was a promising addition to the lineup. The family though questioned the sincerity in Lotta's ultimate acceptance, for ever since a 23andMe genetic test in her late twenties informed her she was fourand-a-half percent Nigerian, her resulting identity crisis was questionably self-medicated with an obsession for conspiracy theories and only speaking in the third person. As a 
result, her children were even more independent than their fellow members of Generation Z. In addition to being a new mom, Robin founded and maintained the highly successful Suburban Dictionary, while twelve-year-old brother Max was already a globally-renowned ambient DJ, famous for tracks like "Peeing Go-Lightly" and "Thunder Down Under."

\section{Music: Hooray! Hooray! Hooray! By Do Make Say Think}

Otto Power: I also like to say, "If you do not enter the tiger's cave, you will not catch its cub."

Ivan Gass: I think it's safe to say all families have their own histories and motivations, leading up to and impacting both the big and little decisions in life. And perhaps at the end of the day, just like the Power family, we are all from a dysfunctional family of sorts, and our somehow successful ability to still navigate the world around us, often creating chaos along the way, is what in fact makes us normal.

\section{Act 3: Actions and Reactions}

Otto Power: I made the mistake of leaving the energy bill from shag. Power out on the table.

Ivan Gass: shag.'s Office of Enforcement \& Oversight, or shag. Power, distributes a weekly power bill to all residents. In conjunction with providing information on individual family member consumption, the bill also displays the top neighborhood consumers and producers of energy in an effort to generate healthy competition and conspicuous production.

Otto Power: Lotta is very competitive. And often overreacts. So, when she saw that we weren't even ranked on the production list, she took matters into her own hands. And unfortunately also tried to teach Max a lesson.

Ivan Gass: Also delivered weekly, though by shag.'s Office of Individual \& Family Affairs, is the shag. Home brochure: a personalized service that through the close monitoring of every home environment can provide detailed recommendations on energy harvesting products and activities to pursue in order to increase at home energy production. In addition, the brochure highlights and provides relevant tips and tricks on a product already owned by the family. In this instance, the shag. Carpet Footprint purchased by the Power family last week. And all these referenced and suggested products are all available for purchase in the Energy of Things catalog, produced by the Office of Innovation \& Technology, or shag. IT.

Otto Power: She hid his headphones. I'm not actually sure where since he still hasn't found them. And while he was running around wild searching for them - poor man is pretty upset, he had a great idea this morning for his next recording - he did actually generate quite a lot of electricity.

Ivan Gass: But also in his frenzy, Max unfortunately woke sleeping Minnie, Robin's daughter, who was sucking on the Pacify-Her, an energy harvesting pacifier, which was charging Robin's cellphone. And as Minnie started crying in response to the ruckus, Robin received a new submission to Suburban Dictionary. Though as the Pacify-Her fell to the floor, Robin's phone instantly died and she was unable to monitor the incoming proposal. But like any great business woman, or desperate teenager, her instincts prevailed and she began sucking on the Pacify-Her herself.

Otto Power: I mean honestly, can you blame what I did? I really wanted, no needed, to watch the morning news, but Lotta had disconnected the television from the central energy system until the shag. Carpet Footprint harvested a high enough quota to get us on next week's ranking. And looking at Robin ridiculously sucking on the damn PacifyHer, I couldn't resist the opportunity to Instagram it. See, I knew she'd get upset at me, but since she was wearing the 

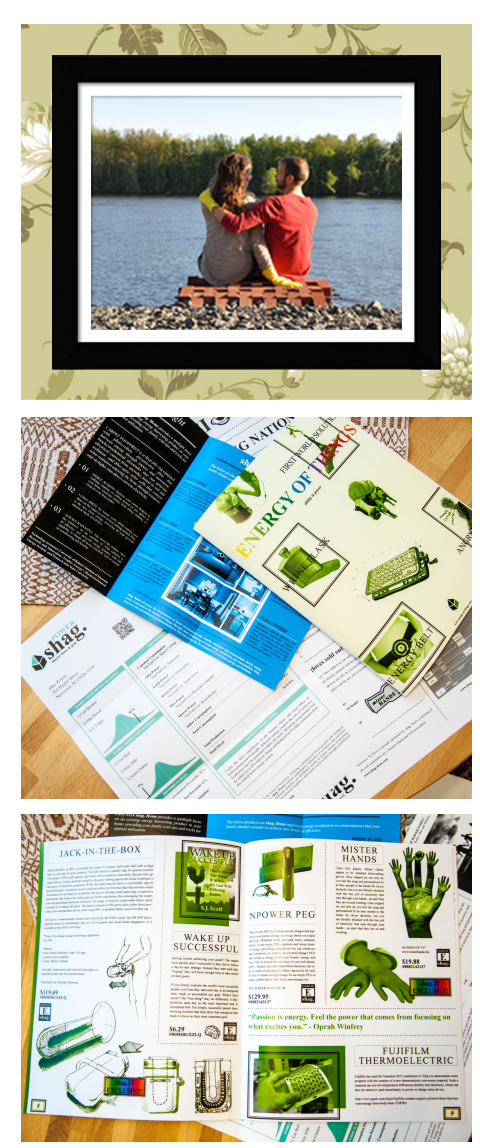

Figure 6: Exhibition artifacts from top to bottom: photograph of Otto and Lotta Power; energy bill, home brochure, and catalog; spread from the Energy of Things catalog. (c) Karey Helms.
Temper Trap, her anger could, and would, generate enough electricity to power the TV.

Ivan Gass: What Otto didn't anticipate though was that during Robin's resulting tantrum, as she heated up both figuratively and literally, she would then turn the air conditioning on high. And it wasn't disconnected from the central energy system... thus consequently canceling out all energy produced by Max on the shag. Carpet Footprint. Leaving the Power family, powerless.

Which leaves me to wonder as the Energy of Things catalog is transitioned into a federal program in the coming months - What will you do? How will you act? What if you were required to produce all the energy you desire to consume?

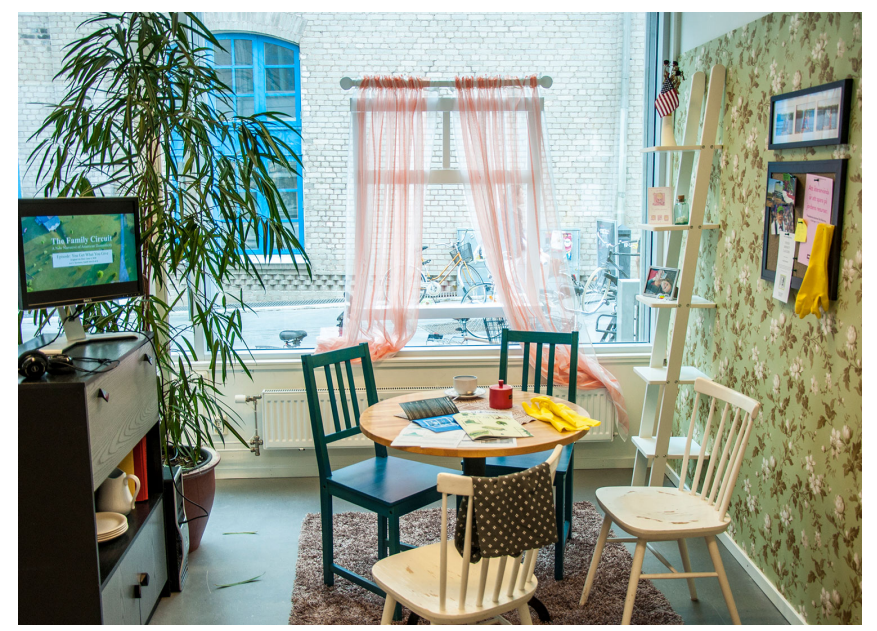

Figure 7: Room of Power family exhibited at Swedish design school and technology corporation. (c) Karey Helms.

\section{Use of the Scenario}

The narrative was used to design an exhibition space of a room from the home of the Power family (see Figures 6 and 7 ). While the radio show was accessible through headphones, the dispersing of diegetic prototypes was to encourage a stumbling upon and gradual perusing of details. In contrast to the absurdity of humorous details, the ordinary room provided observers with time and space to reflect upon the narrative and artifacts as boundary objects to discuss implications of such a lifestyle. This breaking of the fourth wall, or theatrical boundary, by inviting the audience into the space was for comic relief of potential tension caused by the implied continuation of the suffering [28].

Prior to exhibitions, the diegetic prototypes, room design, and radio show were formally presented to two design practitioners and two academic researchers on an examination committee with an audience of over twenty design students. This public presentation was forty-five minutes long, structured by the radio show with supplemental details presented in-between acts. Discussions followed for forty-five minutes.

The room was later exhibited for two weeks in a design school and two days at an industry event. While at the design school, two three-day events took place, including an associated undergraduate degree show and an academic research conference with visitors including students, practitioners, $\mathrm{HCl}$ researchers, exhibitor relatives, and the general public. The private industry event took place at a multi-national technology corporation that collaborates with automotive, manufacturing, and telecom sectors. Multiple five-minute presentations were given followed by one-onone discussions with industry practitioners. 


\section{Discussion}

Lessons learned draw upon responses from design students involved in the production, design practitioners at the examination, and industry professionals at exhibitions.

\section{Reception and Repertoire}

A core dilemma experienced throughout the production was not only how humor in the project would be received, but also how design students involved would be received. As Master's students aspiring to enter industry, there was a competing concern for personal and professional reputation versus the development of a design repertoire [15]. When asked to reflect on her involvement in the project, the infomercial screen actress and then design student remembered feeling "awkward since I played bored-and-sexually frustrated-housewife. Not awkward, maybe embarrassed is maybe better?" yet also stated that, "it was fun to be a part of someone else's creative process. I mean, I sort of gain experience in case I would to make my own project of the same type."

The infomercial voice actress, also then a design student and now a designer in industry, expressed similar sentiments and requested to remain anonymous. She reflected, "I was uncomfortable with the idea of an audio clip of me credited with saying 'vigorous hand jobs' would live forever on the internet." But contrasting with this disassociation was an interest in expanding a range of design methods aimed at critique. She stated, "I was curious to see in further detail how a project of that nature was different than a traditional one and what different kinds of questions it would bring up or different tools it would use." Those tools, being innuendos to evoke laughter, highlight the importance of balancing an uncensored design space for an exploration of humor, with a consideration towards differing levels of engagement as the humor reflects beyond the design fiction.
Details and Disbelief

Without mediating the quantity of humor, a difficulty lay in balancing the details that contribute to the narrative versus alienating an audience. For example, a design practitioner during the examination found the design fiction inaccessible due to "an overload of non-information." In contrast, others appreciated a shift in accountability enabled by the quirky traits and exaggerated details. A design student at the examination remarked, "I really like the fishbowl effect, to see these completely absurd examples, watching them, and then as I sit in my real life I start seeing these absurd things, that we actually do, and I start thinking about energy. That actually opens it up for me, rather than the pressure of, well, how can we [find a solution]. For me it takes the load off." Though different in effect and perhaps indicative of the flow of details, both responses suggest a suspension of belief as the scenario is clearly not real.

Moreover, how details might contribute to a complimentary suspension of disbelief for designers of design fictions, and thus also an audience, needed to be considered. As the first author navigated between a designer of and within a story world, the latter required immersively engaging with details such as the shag. branding guidelines (Figure 1), which though they reflect an implicit critique of corporate aesthetics, result in plausibility. Similarly, many of the bizarre family traits and interactions, such as genetic testing and future professions, also contained relatable threads for being rooted in real fears, aspirations, and experiences shared by participants during ideation. Commenting on the familial interactions, a design student at the examination remarked, "I think the level of detail that you used to describe these stories were actually very good because if you were to imagine a family [...] in any daily ritual like breakfast, if you really zoom in, any family would probably look like a really random chain of events." Thus, the ability for designers 
themselves to fluctuate between belief and disbelief was necessary to achieve a balance of plausibility without deception.

\section{Boundary Objects and Spaces}

Although the scenario was intended primarily as a tool for creating an exhibition rather than an outcome as in the examination, the responses to both events reflected upon the role of boundary objects and spaces to mitigate a flow of humor. At the examination, a design practitioner began with, "Where do I start? You really worked through this, it is a fantastic piece. Maybe the humor overshadows the entire thing." The flow of humor masked the message and froze a response as the radio show obscured the mail as intended boundary objects. As elaborated by a design student, "basically what you do is drop the curtain [...] it needs to be a more gradual transition between the situation these people are in, and then some moment there for us to pause to think." As a result, unintended boundary objects emerged, such as Figure 8: an artifact of the design process that was used in the examination as visual support. As described by another design student, "The chart made it balance. [...] What I feel is the big takeaway that you have designed, you've looked at the interpersonal connections, not only how would you relate to energy, but how would our relationships [relate to energy]."

At the exhibition, another unintended boundary object emerged. While sitting at the table, an automotive professional commented, "This is exactly how I feel: trapped. I design cars but know it's bad for the environment, so I actually ride my bike to work." Although not explicitly referenced, his affirmation of empathy might have resided in the uncanny embedding of the radio show featuring a family within the home of said family, suggesting the exhibition as a boundary space enabled by a "human-scale" design fiction in which the au-

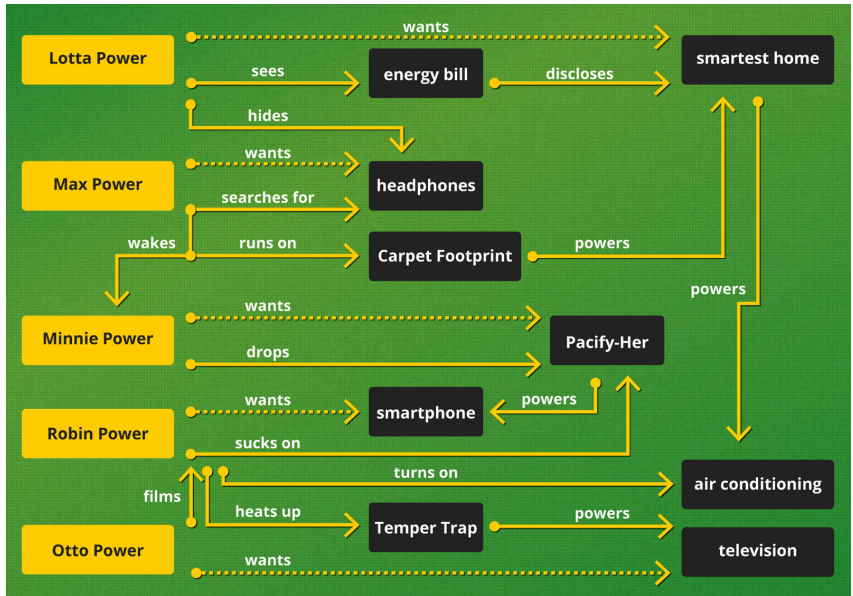

Figure 8: Diagram of interactions between family members, an artifact of the narrative design process. (c) Karey Helms.

dience could step into the layered world. Similar to the examination, industry professionals at the exhibition eventually turned their attention to the mail, or most commonly the Energy of Things catalog, for discourse regarding the ethics of labor in the Pacify-Her and social concerns regarding intimate products.

\section{Post-mortem Reflection}

There is a long history of political satire that engages with humor in the delivery and analysis of news [10]. The political humor used in this scenario, created in 2014 but set in 2018, drew upon incongruity theory to elicit laughter due to the noticeable difference between what is described and what is the norm [28]. For example, the environmentally concerned president appointed a leader Dick Tator, a pun of "dictator", to govern Newtown. An attempt at humor could be found in this nonthreatening joke that contrasts with 
then President Obama's cool demeanor and promise of hope. Though representing political participation, this tactic hedged making a political argument for or against Obama as it aimed to surface, rather than side with, polarizing issues. Thus, this portrayal of an incongruent political utopia enabled unifying entertainment for discourse and lightened the dark humor.

Now that the near-future is present-day, the 2016 election has taken place and resulted in Donald Trump assuming office. This significant event can be interpreted to have changed the meaning of many satirical elements that describe the political context. For example, the name Dick Tator might no longer be interpreted as incongruent, the Clean Party might have shifted from an environmental pun to contain racial undertones, and the American-made energy policy might speak to nationalist policies. These interpretations result in a humor that no longer unifies but instead divides by taking an irreverent tone and position towards the President. While the scenario might still be considered funny, it is no longer through incongruity and instead through superiority, in which it asserts the shortcomings of others [28]. Through this contemporary lens, the political climate of the design fiction shifts from a utopia to a dystopia due to the floating nature of humor.

\section{Acknowledgements}

Many thanks to students and faculty from Umeå Institute of Design for their participation and support, and in particular, Niklas Andersson for his enthusiasm and supervision of the project. All images $@ 2018$ Karey Helms.

\section{REFERENCES}

1. Teresa Almeida, Rob Comber, Gavin Wood, Dean Saraf, and Madeline Balaam. 2016. On Looking at the Vagina Through Labella. In Proceedings of the 2016 $\mathrm{CHI}$ Conference on Human Factors in Computing
Systems (CHI '16). ACM, New York, NY, USA, 1810-1821.

2. Sara Backlund, Magnus Gyllenswärd, Anton Gustafsson, Sara llstedt Hjelm, Ramia Mazé, and Johan Redström. 2006. STATIC! The Aesthetics of Energy in Everyday Things. In Proceedings of the Design Research Society Wonderground International Conference 2006. 14.

3. Julian Bleecker. 2009. Design Fiction: A Short Essay on Design, Science, Fact and Fiction. Near Future Laboratory.

4. Mark Blythe. 2014. The Hitchhiker's Guide to Ubicomp: Using Techniques from Literary and Critical Theory to Reframe Scientific Agendas. Personal Ubiquitous Comput. 18, 4 (April 2014), 795-808.

5. Mark Blythe, Kristina Andersen, Rachel Clarke, and Peter Wright. 2016. Anti-Solutionist Strategies: Seriously Silly Design Fiction. In Proceedings of the 2016 CHI Conference on Human Factors in Computing Systems (CHI '16). ACM, New York, NY, USA, 4968-4978.

6. Whole Earth Catalog. 2018. Stay Hungry Stay Foolish. (2018). http://www. wholeearth. com/index.php

7. Alan Cooper, Robert Reimann, David Cronin, and Christopher Noessel. 2014. About Face: The Essentials of Interaction Design, 4th Edition. John Wiley Sons.

8. Paul Coulton, Joseph Lindley, and Haider Ali Akmal. 2016. Design Fiction: Does the search for plausibility lead to deception?. In Proceedings of DRS 2016, Design Research Society 50th Anniversary Conference. Brighton, UK, 16. 
9. Sally Jo Cunningham and Matt Jones. 2005.

Autoethnography: A Tool for Practice and Education. In

Proceedings of the 6th ACM SIGCHI New Zealand

Chapter's International Conference on

Computer-human Interaction: Making $\mathrm{CHI}$ Natural

(CHINZ '05). ACM, New York, NY, USA, 1-8.

10. Jenny L. Davis, Tony P. Love, and Gemma Killen. 2018 Seriously funny: The political work of humor on social media:. New Media \& Society (March 2018).

11. Carl DiSalvo. 2016. The Irony of Drones for Foraging: Exploring the Work of Speculative Interventions. In Design Anthropological Futures, Rachel Charlotte Smith, Kasper Tang Vangkilde, Mette Gislev Kjaersgaard, Ton Otto, Joachim Halse, and Thomas Binder (Eds.). Bloomsbury Press, 139-154

12. Paul Dourish and Genevieve Bell. 2014. "Resistance is Futile": Reading Science Fiction Alongside Ubiquitous Computing. Personal Ubiquitous Comput. 18, 4 (April 2014), 769-778.

13. Anthony Dunne and Fiona Raby. 2004. Is This Your Future? (2004). http:

//www.dunneandraby.co.uk/content/projects/68/0

14. Anthony Dunne and Fiona Raby. 2013. Speculative Everything: Design, Fiction, and Social Dreaming. MIT Press.

15. Ylva Fernaeus and Anders Lundström. 2015. Practicing Design Judgement through Intention-Focused Course Curricula. Design and Technology Education 20, 1 (Jan. 2015), 47-58.

16. Adrian Forty. 1986. Objects of Desire: Design and Society, 1750-1980. Thames and Hudson.
17. Bill Gaver, Tony Dunne, and Elena Pacenti. 1999. Design: Cultural Probes. Interactions 6, 1 (Jan. 1999), 21-29.

18. William W. Gaver, John Bowers, Kirsten Boehner, Andy Boucher, David W.T. Cameron, Mark Hauenstein,

Nadine Jarvis, and Sarah Pennington. 2013. Indoor Weather Stations: Investigating a Ludic Approach to Environmental $\mathrm{HCl}$ Through Batch Prototyping. In Proceedings of the SIGCHI Conference on Human Factors in Computing Systems (CHI '13). ACM, New York, NY, USA, 3451-3460.

19. Sabrina Hauser, Audrey Desjardins, and Ron Wakkary. 2014. Sfuture: Envisioning a Sustainable University Campus in 2065. In Proceedings of the 2014 Companion Publication on Designing Interactive Systems (DIS Companion '14). ACM, New York, NY, USA, 29-32.

20. Lars Erik Holmquist. 2005. Prototyping: Generating Ideas or Cargo Cult Designs? Interactions 12, 2 (March 2005), 48-54

21. David Kirby. 2010. The Future is Now: Diegetic Prototypes and the Role of Popular Films in Generating Real-world Technological Development. Social Studies of Science 40, 1 (Feb. 2010), 41-70.

22. David A. Kirby. 2011. Lab Coats in Hollywood: Science, Scientists, and Cinema. MIT Press. Google-Books-ID: uMzxCwAAQBAJ.

23. Ilpo Koskinen. 2011. Confusions: How Design Research Meets Art and Design. (2011). http://ilpokoskinen. com/media/Confusions.pdf

24. This American Life. 2018. Public Radio Program (2018). https://www.thisamericanlife.org/about 
25. Joseph Lindley. 2015. A Pragmatics Framework for Design Fiction. In Proceedings of the European Academy of Design Conference.

26. Matt Malpass. 2013. Between Wit and Reason: Defining Associative, Speculative, and Critical Design in Practice. Design and Culture 5, 3 (Nov. 2013), 333-356.

27. Thomas Markussen and Eva Knutz. 2013. The Poetics of Design Fiction. In Proceedings of the 6th International Conference on Designing Pleasurable Products and Interfaces (DPPI '13). ACM, New York, NY, USA, 231-240

28. John C. Meyer. 2000. Humor as a Double-Edged Sword: Four Functions of Humor in Communication. Communication Theory 10, 3 (Aug. 2000), 310-331.

29. Lene Nielsen. 2002. From User to Character: An Investigation into User-descriptions in Scenarios. In Proceedings of the 4th Conference on Designing Interactive Systems: Processes, Practices, Methods, and Techniques (DIS '02). ACM, New York, NY, USA, 99-104.

30. David E. Nye. 1992. Electrifying America: Social Meanings of a New Technology, 1880-1940. MIT Press. Google-Books-ID: dAEIGDvk2yUC.

31. James Pierce and Eric Paulos. 2010. Materializing Energy. In Proceedings of the 8th ACM Conference on Designing Interactive Systems (DIS '10). ACM, New York, NY, USA, 113-122.

32. James Pierce and Eric Paulos. 2011. A Phenomenology of Human-electricity Relations. In Proceedings of the SIGCHI Conference on Human Factors in Computing Systems (CHI '11). ACM, New York, NY, USA, 2405-2408.
33. James Pierce and Eric Paulos. 2012. The Local Energy Indicator: Designing for Wind and Solar Energy Systems in the Home. In Proceedings of the Designing Interactive Systems Conference (DIS '12). ACM, New York, NY, USA, 631-634.

34. James Pierce, Diane J. Schiano, and Eric Paulos. 2010. Home, Habits, and Energy: Examining Domestic Interactions and Energy Consumption. In Proceedings of the SIGCHI Conference on Human Factors in Computing Systems (CHI '10). ACM, New York, NY, USA, 1985-1994.

35. Asreen Rostami, Chiara Rossitto, Donald McMillan, Jocelyn Spence, Robyn Taylor, Jonathan Hook, Julie Williamson, and Louise Barkhuus. 2017. Glimpses of the Future: Designing Fictions for Mixed-reality Performances. Interactions 25, 1 (Dec. 2017), 46-51.

36. Steven E. Sexton and Alison L. Sexton. 2014. Conspicuous conservation: The Prius halo and willingness to pay for environmental bona fides. Journal of Environmental Economics and Management 67, 3 (May 2014), 303-317.

37. Herbert A. Simon. 1996. The Sciences of the Artificial MIT Press.

38. Christofer Skurka, Jeff Niederdeppe, Rainer Romero-Canyas, and David Acup. 2018. Pathways of Influence in Emotional Appeals: Benefits and Tradeoffs of Using Fear or Humor to Promote Climate Change-Related Intentions and Risk Perceptions. Journal of Communication 68, 1 (Feb. 2018), 169-193.

39. SkyMall. 2018. Online Shopping Catalog, Unique Gifts Travel Accessories. (2018). https://skymall .com/ 
40. Bruce Sterling. 2012. Sci-Fi Writer Bruce Sterling

Explains the Intriguing New Concept of Design Fiction (Interview by Torie Bosch). (2012).

http://www.slate.com/blogs/future_tense/2012/

03/02/bruce_sterling_on_design_fictions_.html? via $=$ gdpr - consent

41. Marie Louise Juul Søndergaard and Lone Koefoed Hansen. 2016. PeriodShare: A Bloody Design Fiction. In Proceedings of the 9th Nordic Conference on Human-Computer Interaction (NordiCHI '16). ACM, New York, NY, USA, 113:1-113:6.

42. Mark Weiser. 1991. The Computer for the 21st Century. Scientific American 265, 3 (1991), 94-104.
43. Yeonsu Yu and Tek-Jin Nam. 2014. Let's Giggle!: Design Principles for Humorous Products. In

Proceedings of the 2014 Conference on Designing Interactive Systems (DIS '14). ACM, New York, NY, USA, 275-284.

44. John Zimmerman, Jodi Forlizzi, and Shelley Evenson. 2007. Research Through Design As a Method for Interaction Design Research in $\mathrm{HCl}$. In Proceedings of the SIGCHI Conference on Human Factors in

Computing Systems (CHI '07). ACM, New York, NY, USA, 493-502. 